\title{
Fatty crystals in sclerema neonatorum ${ }^{1}$
}

\author{
C. PROKŠ AND V. VALVODA \\ From the Ounz Hospital, Pisek, and the Department of Solid State Physics, \\ Charles University, Prague, Czechoslovakia
}

SYNOPSIS The fatty crystals in three previously published cases of sclerema neonatorum were identified by means of $x$-ray diffraction as sodium stearate and palmitic acid. A composite view of the pathogenesis of both sclerema neonatorum and adiponecrosis cutis neonatorum is discussed.

The chemical specificity of human neonatal fat, i.e., its relatively high content of palmitic and stearic acids, has a definite morphological counterpart. In frozen sections of subcutaneous tissue of infants up to 6 months of age there are almost constantly to be found small, needle-like fatty crystals within the adipose cells. These crystals were named 'margarine' crystals by early authors, but in recent years they have attracted little attention. It is, however, of interest that two rather rare disorders of the neonatal period, namely, sclerema neonatorum and adiponecrosis cutis neonatorum, only affect human subcutaneous fat which is 'oversaturated' chemically and marked by the presence of 'margarine' crystals morphologically. On the basis of four thoroughly studied cases of sclerema neonatorum and histological examination of the skin and subcutaneous tissue in over a hundred routine necropsies (Prokš, $1961,1964)$, we have reached the following conclusions.

The margarine crystals are dispersed through the adipose tissue in small amounts in about $95 \%$ of normal (non-sclerematous) infants. The crystals occur in two distinct forms: very small crystals scattered without any definite pattern within the fat cells, and comparatively large crystals arranged in rosettes. We have named the first type 'A crystals' and the second ' $\mathrm{B}$ crystals'.

In early cases of sclerema neonatorum the subcutaneous adipose cells were completely filled with A crystals of relatively large size. In a case of sclerema of longer duration, there were, in addition, many substantially larger crystals of the B type comparable to those which are constantly encountered in adiponecrosis cutis neonatorum.

In sclerema cases, when A crystals alone were present, there was marked broadening of the sub-

'Read at the Vth Congress of the International Academy of Pathology held in London in June 1964.

Received for publication 23 September 1965. cutaneous fibrous septa due to oedema. The presence of $B$ crystals, on the other hand, was attended by proteinous exudation into the damaged fat cells, by fat necrosis, and by giant-cell granulomatous inflammatory reaction.

In this paper we present the results of $x$-ray diffraction measurements which were carried out in three cases of sclerema neonatorum in order to demonstrate the chemical structure of the crystals in question.

\section{MATERIALS AND METHOD}

Frozen sections were cut in the usual way and stained with haematoxylin and Scharlach $R$, or Nile blue sulphate (Lorrain-Smith). The crystal-containing area of each section was then removed and rolled on a glass capillary tube to which an amorphous adhesive had been applied. These specimens were used for $x$-ray diffraction studies. The $x$-ray diffraction method used is that known as the Debye-Scherrer powder method for 'back reflection'. The equipment included a Micrometa $x$-ray diffraction source unit. Nickel-filter $2 d$ copper $K \alpha$ radiation produced at $35 \mathrm{kv}$. and $27 \mathrm{ma}$. was used. The exposure time varied from four to six hours. The distance between the specimen and the film was $50 \mathrm{~mm}$.

\section{RESULTS}

The $x$-ray powder diffraction patterns obtained were converted to $d$-values and relative intensities $\left(I / I_{1}\right)$. The $\mathrm{d}$-values for all tissue patterns were calculated for $\lambda(\mathrm{CuK} a)=1.5405 \AA$. I is the estimated intensity of any particular line, while $I_{1}$ is the intensity of the strongest line. Using the $\mathrm{d}$-values of the three strongest lines, reference was made to the powder data file (Philadelphia, 1958) for comparison with the unknown. The d-values were simply converted into diagrams (Figs. 1 and 2) in which the breadth and darkness of the lines represent the intensity of the original lines. The possibility that formol fixation 


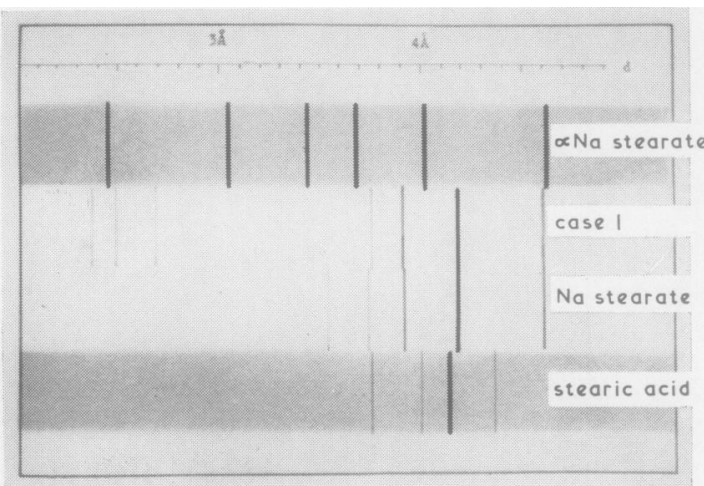

FIG. 1. The graph is showing the d-values and relative intensities of reflection lines for case 1 . The patterns of sodium stearate, alpha sodium stearate, and stearic acid are included for comparison.

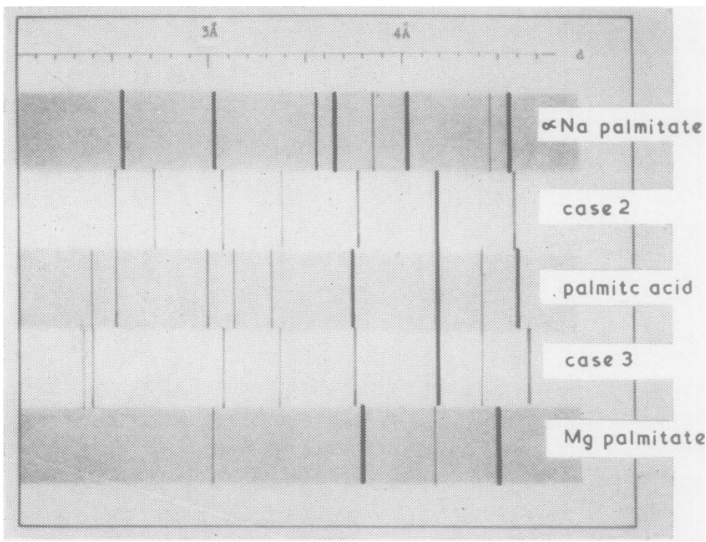

FIG. 2. The $d$-values and relative intensities in cases 2 and 3 with the patterns of palmitic acid, alpha sodium palmitate, and magnesium palmitate.

had caused a change of structure of the crystals under examination was excluded by experiments in which pure specimens of the corresponding substances were used.

Specimens from three cases of sclerema neonatorum were subjected to this analysis with results

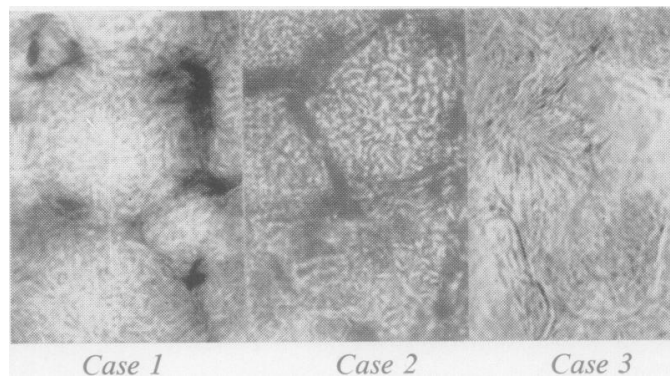

FIG. 3. The morphology of crystals in question. Case haematoxylin and Scharlach $R$, phase contrast, $\times 44$ Case 2: haematoxylin and Scharlach $R, \times 500$. Case Lorrain-Smith, phase contrast, $\times 320$.

which are summarized in Table I. Examples of the crystals are shown in Figure 3.

\section{COMMENT}

The identity of the margarine crystals in "normat infants and in adiponecrosis cutis neonatorum has never been satisfactorily settled. In the past they haves usually been described as 'crystals of fatty acids' without any supporting evidence for this designation Harrison and McNee (1926) tested their melting point and solubility and came to the tentatiog conclusion that they might represent crystallin forms of glycerides of palmitic and stearic acids The observation that these crystals occasionaly dissolve after prolonged immersion of the tissue in formalin, or when sections are treated with distilled water or dilute acetic acid, led us to speculate that they might be sodium and potassium soaps of fat acids (Prokš, 1961, 1964). It was to test this hypo thesis that the present investigation was undertakew.

The method of $x$-ray diffraction analysis known the Debye-Scherrer powder method for 'back reflection' was first used in pathology by Parsons and Eurs (1959). Although the method is rather elaborate and is likely to require the cooperation of a depare ment of physics, we believe that $x$-ray diffractio might often be of value in the examination of crystap containing pathological material, even when the

TABLE I

ANALYSIS OF THREE SPECIMENS FROM CASES OF SCLEREMA NEONATORUM

\begin{tabular}{|c|c|c|c|c|}
\hline Case No. & Type of Crystals & Tissue Reaction & Chemical Structure & $\begin{array}{l}\text { Reference for Further } \\
\text { Information }\end{array}$ \\
\hline 1 & $\mathbf{A}$ & $\begin{array}{l}\text { Inflammatory oedema of subcutaneous fibrous } \\
\text { septa }\end{array}$ & $\begin{array}{l}\text { Sodium stearate } \\
\mathrm{Na}\left(\mathrm{C}_{17} \mathrm{H}_{35} \mathrm{COO}\right)\end{array}$ & Proks (1961) case 1 \\
\hline 2 & $\mathbf{A}$ & Oedema of subcutaneous fibrous septa & $\begin{array}{l}\text { Palmitic acid } \\
\mathrm{CH}_{3}-\left(\mathrm{CH}_{2}\right)_{14}-\mathrm{COOH}\end{array}$ & Prokš (1961) case 2 \\
\hline 3 & $A$ and $B$ & $\begin{array}{l}\text { Intracellular exudation of protein, incipient fat } \\
\text { necrosis, giant-cell granulomas }\end{array}$ & $\begin{array}{l}\text { Palmitic acid for both types } \\
\mathrm{CH}_{2}-\left(\mathrm{CH}_{2}\right)_{14}-\mathrm{COOH}\end{array}$ & Prokక (1964) case 2 \\
\hline
\end{tabular}
. 
amount of material available for testing is very small.

The subdivision of fatty crystals into $A$ and $B$ types according to their morphological appearances seems to be justified by the different types of reaction induced in the surrounding tissues by these two types of crystal. However, the present investigation has shown that with these crystalline breakdown products of fat in the subcutaneous adipose tissue the crystal form is independent of its chemical structure.

The B crystals occur both as post-mortem breakdown products in 'normal' macerated foetuses (Prokš, 1964) and as a phenomenon during life, being readily recognized as such in cases of adiponecrosis cutis neonatorum. They have even been described in normal infants in lesions resulting from B.C.G. vaccination where they were connected with the formation of Schaumanm bodies (Vortel, 1962). The formation of A crystals during life can hardly be denied in morphologically typical cases of sclerema neonatorum (Prokš, 1961). In normal infants, however, the occurrence of A crystals during life is less certain owing to their slight capacity to produce an inflammatory reaction in the surrounding tissues. We believe that they are quite often present in small amounts in liveborn infants as an expression of a clinically inapparent dystrophy in the neonatal subcutaneous fat. When aetiological factors for adiponecrosis cutis neonatorum are present at the same time, the small A crystals recrystallize as the large B crystals with resultant fat necrosis and giant-cell granulomatous inflammatory reaction. On the other hand, the excessive formation of A crystals results in the rare clinical picture of sclerema neonatorum. If this condition persists for a sufficient length of time, some of the A crystals may recrystallize as the $B$ type and a mixed histological pattern of sclerema and adiponecrosis cutis would therefore result. Thus, these two diseases may be considered closely akin to one another while their genesis may be sought in the two above-mentioned different types of dystrophy in the neonatal subcutaneous fat.

\section{REFERENCES}

ASTM X-ray Powder Data File. Philadelphia, 1958.

Harrison, G. A., and McNee, J. W. (1926). Arch. Dis. Childh., 1, $63,123$.

Parsons, J., and Eurs, F. J. (1959). Amer. J. clin. Path., 32, 405.

Proks, C. (1961). Zbl. allg. Path. path. Anat., 102, 505.

(1964). Virchow's Arch. path. Anat., 337, 584.

Vortel, V. (1962). Ibid., 336, 46. 